\title{
An Exploratory Study of American Muslim Conceptions of Mental Illness
}

\author{
Anisah Bagasra and Mitchell Mackinem \\ Claflin University, Orangeburg, South Carolina
}

\section{Abstract}

\begin{abstract}
Theological expressions on physical and mental illness tend to be influential in shaping the beliefs of practitioners living in Muslim majority societies.. It is unknown what influence, if any, Islamic beliefs have on the conceptions of mental illness expressed by Muslim Americans. This study explores the conceptions of Muslim Americans regarding mental illness. Two hundred and fifty-five individuals identifying as Muslim American participated in a mixed-method anonymous survey. The results of the survey reveal that most Muslim American participants adhere primarily to the dominant Western biomedical model of mental illness, but open-ended responses reflect a more complex understanding of mental illness as having biological, environmental, and psycho-spiritual origins. Findings suggest that how a Muslim American interprets mental illness will most likely depend upon the symptoms and context of the illness. Further exploration is needed to understand the beliefs of Muslim Americans and the way in which these beliefs affect attitudes toward therapies and mental health services.
\end{abstract}

\section{Introduction}

Muslim Americans are an increasingly visible minority group within the American population. Though of diverse heritage, they share a common identity as followers of Islam that includes beliefs, values, and core practices. Islam, like other religious traditions, has historical conceptions of mental illness and traditional modes of psychotherapy (Al-Subaie \& Alhamad, 2000; Hammoud, White, \& Fetters, 2005; Hedayat-Diba, 2000; Husain, 2006). These traditional beliefs include spiritual and supernatural origins for illness. Very little psychosocial research has been conducted involving Muslim Americans to discover 
the existence of beliefs, perceptions, or attitudes that may pose a barrier to help-seeking for mental health issues. This paper explores beliefs among Muslim Americans about mental illness in order to understand how, if at all, religion influences the way they conceptualize mental illness.

\section{Muslims in the United States}

Muslim immigrants have been a small but consistent presence in the United States since colonial times. Arriving first as slaves primarily from West Africa (Gomez, 1994), Muslim immigrants began to arrive voluntarily from several Near-Eastern and Central Asian countries in the early $20^{\text {th }}$ century (Nyang, 1999; Wormser, 2002). The number of Muslim immigrants to the United States increased during the cold war years and continued growth has been noted as a result of regional conflicts (Coughlan \& Owens-Manley, 2005; Ratliff, 1997). Births and conversions have also consistently contributed to the population over the last century (Pew, 2007). Muslims are therefore a diverse and persistent part of America's immigrant ancestry.

The number of Muslims in the United Sates is unclear with estimates ranging from 2 to 11 million people (Haddad, 2004; Stone, 1991). Most researchers agree that the population growth is significant and continues to grow rapidly due to immigration, conversion, and births. The population is also increasingly diverse, with a little more than half identifying as foreign-born immigrants (Pew, 2007) from over 50 different countries. Of those who are native-born, $20 \%$ identified themselves as African-American and $15 \%$ as belonging to an ethnicity other than African-American. Twenty-one percent of the native-born Muslims identified themselves as converts to Islam, and 14\% stated that they were born Muslim (Pew, 2007, p. 7).

\section{Conceptions of Mental Illness in the United States}

Lay conceptions of mental illness in the United States, particularly related to the cause of mental illness, tend to differ dramatically from the accepted definitions within the clinical community. For example, the lay population may interpret a DSM-defined mental disorder as God's will (Link et al., 1999; Wesselmann \& Graziano, 2010), a sign of weakness Schnittker, Freese \& Powell, 2000), or a result of upbringing (Kuppin \& Carpiano, 2006). Many lay definitions tend to be broader, and exclude many symptoms used in the diagnostic manual (Granello \& Granello, 2000; Harland et al., 2009; Pescosolido et al, 2000; Link, Phelan, Beshnahan, Stueve, \& Pescosolido, 1999; Kuppin \& Carpiano; 2006). Given a lack of agreement among mental health professionals and between professionals and lay people regarding what is and what causes mental 
illness, there continues to be a discrepancy in understanding what constitutes a mental illness in American society.

\section{Islamic Conceptions of Mental Illness}

Historical Islamic conceptions of mental illness can be divided into three categories: (a) theoretical concepts developed by Islamic philosophers, religious leaders, and scholars; (b) theologically derived positions based upon the Qur'an and prophetic traditions (the latter category called both sunnah and hadith); and (c) the lay beliefs of individuals and groups in traditional Muslim societies. These beliefs include definitions of mental illness, causes, and predictors of mental illness that are commonly found within traditional Muslim societies, classification of symptoms, and proscribed treatment methods.

The traditional Islamic conception of mental illness asserts that all mental and behavioral dysfunction has a psycho-spiritual root and can be directly tied to an individual's higher spiritual awareness of his or her Creator (Athar, 1993; Husain, 2006; Shafii, 1988; Haque 2004. An explanation of what constitutes dysfunction is elusive, and has changed over time depending upon the cultural and social contexts. "Sickness of the Heart" or "Diseases of the Heart" (in Arabic amrad al-qalb) are terms generally used in Islam to describe illnesses of a psycho-spiritual nature. Due to core beliefs in predestination and the transcendent and omnipotent nature of God, Muslims also tend to view psychological disorders as a test from God, God's will, and a form of punishment for sin (Husain, 1998).

Islamic tradition also recognizes supernatural connections to mental illness. Prophetic traditions record various incidents that involve jinn, evil eye, and black magic (El-Zein, 2009) and in several traditions, it is recorded that he recited particular prayers to ward off evil jinn and black magic. The presence of these narratives has been, and continues to be, the legitimizing factor for supernatural causes of mental illness. Severe symptoms of psychopathology, including hallucinations, nightmares, extreme lethargy, and physical symptoms with no known physical causes are often attributed to Jinn possession in Muslim majority countries (Husain, 1998; Speziale, 2003). The Qur'an and hadith identify the jinn as spirit entities capable of appearing in different forms, and of acting in a beneficent or harmful manner toward humankind (Ameen, 1992). The attribution of mental illness to possession by jinn has been documented in contemporary Muslim populations in South Asia, South Africa, and the Arab world (Al-Adawi et al., 2002; Al-Issa, 2000; Ally \& Laher, 2008).

The idea of the evil eye reflects similar conceptions that mental illness can be caused by external, supernatural forces Affliction with the evil eye is said to occur when a person looks or speaks with envy of another person, or when an 
individual fails to acknowledge God after a compliment. An example would be telling a parent how beautiful their child is, without following this statement with Mashallah (God has willed it). Bali (2004) discusses the prophetic traditions related to the evil eye: "According to Ibn Hajar [a medieval Islamic scholar], the evil eye is a glance combined with jealousy that comes from a despicable person to affect another" (p. 180). Abu-Rabia (2005) discusses belief in the evil eye among the Bedouin tribes and states: "Belief in the evil eye is constantly present in people's lives, alongside beliefs about spirits, jinns and other demons, and it has serious implications for how individuals perceive the world and their place in it" (p. 241).

Interpretations of the cause of mental illness as a combination of both supernatural and social factors has been found by researchers in Southeast Asia (Azhar \& Varma, 2000; Haque, 2010), Gulf nations (El-Islam, 2000), North Africa (Endrawes, O’Brien, \& Wilkes, 2007; Fadlalla, 2005; Stein, 2000), and Pakistan (Mubbashar, 2000; Saeed, Gater, Hussain, \& Mubbashar, 2000). Many of these researchers also note the continued presence of belief in mental illness as a direct result of the evil eye, God's will, or God's punishment in Muslim countries and in Muslim immigrant and refugee populations in the United States (El-Islam, 1982; Fadlalla, 2005; Haque, 2010; Kemp, 2007; Martin, 2009). These beliefs seem to be moderated by factors such as level of education and exposure to contemporary Western concepts of psychopathology.

The traditional Islamic psycho-spiritual understandings of mental illness bear little resemblance to modern day problems that are categorized in contemporary Western texts as mental illness. However, the "states" of illness that are described in traditional Islamic texts, often led to symptoms that many of us recognize today, such as obsessions, anxiety, depression, delusions, hallucinations, and hypochondria (Alawi, 1992; Al-Issa, 2000; Husain, 2006; Shafii, 1988). Historically, Muslims viewed these symptoms as having originated from a lack of faith or immoral behavior. The findings of contemporary research studies on mental illness in predominantly Muslim countries continue to support a multidimensional model of understanding mental illness as having supernatural, social, and biological causes. No one model of mental illness is accepted within the various populations, and, in many cases, the supernatural model continues to dominate (see Farooqi, 2006; Abu-Rabia, 2005; Endrawes, O’Brien \& Wilkes, 2007; Johnsdotter, Ingvarsdotter, Ostman, \& Carlbom, 2011, Haque, 2008).

The idea that multiple explanations for the cause of mental illness can coexist in contemporary Muslim thought may be confounding to those outside the tradition. Muslims, particularly religious leaders, traditional healers, and individuals who are unexposed to Western medical modalities, believe that spiritual and social causes of mental illness are as likely as any physical cause. The beliefs and attitudes of religious leaders in the Muslim world reflect, to 
a certain degree, the beliefs held by many contemporary Muslims living in traditional Islamic societies. What is not understood, however, is the degree to which these beliefs are carried over into the United States, or embraced by American-born Muslims. This study seeks to understand how, if at all, traditional Islamic conceptions of mental illness manifest within the American Muslim population.

\section{Method}

The theoretical framework and methodological approach were designed to explore the core research question: How do Muslim Americans understand and interpret the concept of mental illness? "Mental illness" is defined for the purpose of this study as dysfunction related to thoughts, perceptions, emotions, or behaviors that result in distress for the individual, impaired functioning, or an increase in suffering.

\section{Survey Instrument}

The survey instrument utilized here has been designed by the author to compensate for the lack of an available instrument that incorporates traditional Islamic conceptions of mental illness outlined in the review of the literature, and that has been tested in previous research for reliability and validity. The survey has been designed to be easy to understand and straightforward. An anonymous survey format was chosen for this study because of stigma related to the topic and a general suspicion of research and researchers that is has been found to be prevalent in the Muslim American population by previous researchers (Amer et al., 2008; Williamson \& Ahmad, 2007; Rippy \& Newman, 2008). The research instrument consists of three sections. The first set of questions centered on demographic information. The Conceptions of Mental Illness scale was designed by examining dozens of existing questionnaires that focus on causes, beliefs, and attitudes toward mental illness. Additional questions were designed to address culturally specific causes and beliefs that are found in Islamic theological descriptions of illness. These were derived from existing research conducted in Muslim-majority countries. The questionnaire uses straightforward statements and a Likert scale response system. Participants indicate their level of agreement with each statement. The instrument was tested with a population of 55 participants who were encouraged to provide feedback. The feedback received from participants was incorporated in order to improve overall survey design, reduce confusion, and avoid ambiguity. An exploratory factor analysis was conducted on the Conceptions of Mental Illness portion of the survey. The factor analysis using maximum likelihood 
and Varimax orthogonal transformation matrix factor rotation produced three factors with eigenvalues greater than 1.0. The conceptions of mental illness questions were divided into three subscales based on the results of the exploratory factor analysis. These subscales represent three separate conceptions: 1) Western biomedical conceptions, 2) traditional Islamic conceptions, and 3) spiritual conceptions (mental illness as a test from God or the Will of God). The third part of the survey consisted of two open-ended questions which allowed participants to address their own definitions of mental illness and additional causes of mental illness not included in the close-ended portion. Data was analyzed using SPSS version 16.0.

\section{Procedures}

Prior to data collection, institutional review board approval was obtained. All potential participants were provided a brief description of the study via either a paper or electronic "cover letter" that informed them of the purpose of the study, potential benefits and risks of participation, and the voluntary nature of their participation. Surveys were distributed to Muslim Americans through both paper distribution and online distribution. The methods of distribution were chosen in order to increase response rates and reach a more diverse segment of the Muslim American population than could be achieved by one method alone. A multi-modal sampling method has been determined to be the best method of survey distribution within the Muslim American population, based on previous large-scale studies (conducted by the Pew Research Center and the Council on American-Islamic Relations (CAIR)), and smaller studies (Aloud \& Rathur, 2009; Rippy \& Newman, 2006).

The method of paper survey distribution was through religiously based organizations and mosques, located primarily in the Southeast region of the United States. Packets included the cover letter and full survey, and were enclosed in brown envelopes. A designated place for completed surveys to be dropped off on-site was determined by the mosque or Islamic center leader, and announced to the congregation.

A second method used to disseminate the survey was through the Internet. The online survey site SurveyMonkey was utilized to provide the survey anonymously to web users. The online survey was distributed by advertising on the social-networking site Facebook, sending the cover letter with a link to the survey to the listservs of Muslim organizations, and through individual emails to Muslim community leaders who were asked to disseminate the survey to friends, colleagues, and community members. The SurveyMonkey link was available for four months. This method of survey distribution relied on the power of snowball sampling to increase response rates across a diverse and geographically diffused population. 


\section{Results}

\section{Participants}

The 255 participants (118 males, 136 females, 1 unidentified) ranged in age from 18 to 98 years old $(M=36.1, S D=15.6)$. Reported marital statuses were single (29\%), married (62.7\%), widowed (0.8\%), divorced (4.7\%), and engaged (2.7\%). Participants' self-reported race or ethnicity was categorized into eight groups: Caucasian/White (13\%), Asian, including South, South East, and Asian Indian (44.5\%), Mixed or Multi-Racial (5.9\%), Middle Eastern/Arab (15.5\%), African American/Black (11.3\%), Native American/American Indian (0.8\%), Hispanic/Latino (1.3\%), and Other (7.5\%).

Nine educational levels were represented among the respondents $(0.8 \%$ less than high school, 17.2\% High school, 10\% Associates degree, 32.4\% Bachelors degree, 20.8\% Masters degree, 5.6\% Doctorate, 1.2\% each J.D. and M.D., respectively, and $0.8 \%$ other). The remaining $10 \%$ did not report their educational level. Forty-two percent of participants were born in the United States, with the remaining $58 \%$ representing 34 different countries of origin.

Years in the United States ranged from 1 to 35 years $(M=17.2, S D=10.9)$ for immigrants. At the time of the study, 58\% of participants reported being employed. Participants were asked to report their region of residence in the United States in order to assess distribution of the survey. As a result of paper distribution in the Southeast, 50.8\% reported residing in that region. The remaining respondents stated their region of residence as $15.5 \%$ the Midwest, $12.3 \%$ as the Northeast, $1.2 \%$ as the Rocky Mountain Region, $3.6 \%$ as the MidAtlantic, $8.7 \%$ as the Southwest, and $7.9 \%$ as the West Coast.

Forty-one participants (16.5\%) identified themselves as converts/reverts to Islam. The number of years since conversion ranged from 1 to 57 years $(M=$ $16.6, S D=13.2)$. Of the 255 participants, 252 answered questions regarding religious orientation. The majority (58.3\%) identified as Sunni, 31.3\% as "Just Muslim," $2 \%$ as Shia, $0.4 \%$ as Bohra, $1.6 \%$ as Ismaili, $0.4 \%$ as Salafi, $5.6 \%$ as Sufi, and $0.4 \%$ as Wahhabi. Participants were also asked to report their level of religious practice, with $61 \%$ identifying their level of practice as "moderate," $18.7 \%$ as "orthodox," $10.8 \%$ as "liberal," $8.3 \%$ as a "very strict practitioner", $0.8 \%$ as "non-practicing," and $0.4 \%$ as "other."

\section{Conceptions of Mental Illness}

Responses to the conceptions of mental illness questions (see Table 1) reflect a general belief that mental illness is a disease, and can therefore be perceived in a way similar to physical disease. Participants were most likely to attribute mental illness to environmental factors such as stress, trauma, poor living envi- 
TABLE 1. Conceptions of Mental Illness

\begin{tabular}{|c|c|c|c|c|c|}
\hline & $\begin{array}{l}\text { Strongly } \\
\text { Agree }\end{array}$ & Agree & $\begin{array}{l}\text { Neither Agree } \\
\text { nor Disagree }\end{array}$ & Disagree & $\begin{array}{l}\text { Strongly } \\
\text { Disagree }\end{array}$ \\
\hline Mental illness is a disease & $37.3 \%$ & $23.5 \%$ & $10.2 \%$ & $14.7 \%$ & $14.3 \%$ \\
\hline M.I. is usually inherited & $2.8 \%$ & $27.4 \%$ & $41.4 \%$ & $23.3 \%$ & $5.1 \%$ \\
\hline $\begin{array}{l}\text { Sinful actions are often the cause } \\
\text { of M.l. }\end{array}$ & $8.3 \%$ & $15.4 \%$ & $28.2 \%$ & $28.2 \%$ & $19.9 \%$ \\
\hline $\begin{array}{l}\text { Stress caused by religious } \\
\text { persecution }\end{array}$ & $22.2 \%$ & $53.2 \%$ & $13 \%$ & $7.9 \%$ & $3.7 \%$ \\
\hline Lack of will power can cause M.I. & $8.3 \%$ & $33.8 \%$ & $26.4 \%$ & $19.9 \%$ & $11.6 \%$ \\
\hline $\begin{array}{l}\text { M. I. is often a result of possession } \\
\text { by jinn }\end{array}$ & $2.8 \%$ & $10.7 \%$ & $29.8 \%$ & $24.6 \%$ & $32.1 \%$ \\
\hline Frequent drug use can lead to M.I. & $27.4 \%$ & $44.2 \%$ & $17.2 \%$ & $8.9 \%$ & $2.3 \%$ \\
\hline M.I. can be caused by the evil eye & $8.8 \%$ & $19.5 \%$ & $31.6 \%$ & $23.8 \%$ & $16.3 \%$ \\
\hline Drinking alcohol will lead to M.I. & $13.5 \%$ & $26.5 \%$ & $34 \%$ & $19.0 \%$ & $7 \%$ \\
\hline $\begin{array}{l}\text { If a person becomes mentally ill, } \\
\text { it is often the will of Allah }\end{array}$ & $35.7 \%$ & $23.9 \%$ & $26.8 \%$ & $8 \%$ & $5.6 \%$ \\
\hline $\begin{array}{l}\text { M.I. is caused chemical imbalances } \\
\text { in the brain }\end{array}$ & $47 \%$ & $33.3 \%$ & $18.2 \%$ & $1.5 \%$ & $0 \%$ \\
\hline M.I. is a test from Allah & $27 \%$ & $28.9 \%$ & $33.2 \%$ & $4.3 \%$ & $6.6 \%$ \\
\hline $\begin{array}{l}\text { M.I. usually comes from tensions } \\
\text { in family }\end{array}$ & $3.7 \%$ & $14 \%$ & $36.9 \%$ & $36.5 \%$ & $8.9 \%$ \\
\hline $\begin{array}{l}\text { If the environment is really bad } \\
\text { anyone can become M.I. }\end{array}$ & $12.6 \%$ & $38.7 \%$ & $23.4 \%$ & $19.2 \%$ & $6.1 \%$ \\
\hline $\begin{array}{l}\text { M.I. can be caused by the use of } \\
\text { black magic }\end{array}$ & $8.4 \%$ & $19.2 \%$ & $29.9 \%$ & $21 \%$ & $21.5 \%$ \\
\hline
\end{tabular}

ronments, and family stressors, as well as behavioral risk factors such as alcohol and drug use.

A majority of participants agreed or strongly agreed that mental illness is caused by chemical imbalances in the brain. In addition, a significant percentage agreed that mental illness should be viewed from a fatalistic perspective, as both the Will of God and a test from God. Fewer percentages agreed that mental illness is caused by supernatural factors such as jinn possession, the evil eye, and black magic. Less than half agreed that mental illness results from a lack of will power, and only $14 \%$ agreed that sinful thoughts and actions cause mental illness. Non-immigrants actually had a higher level of agreement with jinn possession, the evil eye, and black magic as causes of mental illness than immigrants when the data was divided by immigrant status.

On the traditional Islamic conceptions scale (see Figure 1), actual scores fell into the scale range from 4 to 20 . The mean score was $8.8(S D=4.94)$. Of the respondents, $34.1 \%$ had scores in the low range of agreement with traditional Islamic conceptions, $4.7 \%$ had high scores, and $45.8 \%$ had moderate scores reflecting moderate agreement with these conceptions of the causes of mental illness. 
Figure 1. Islamic Conceptions of Mental Illness Subscale - Score distributions

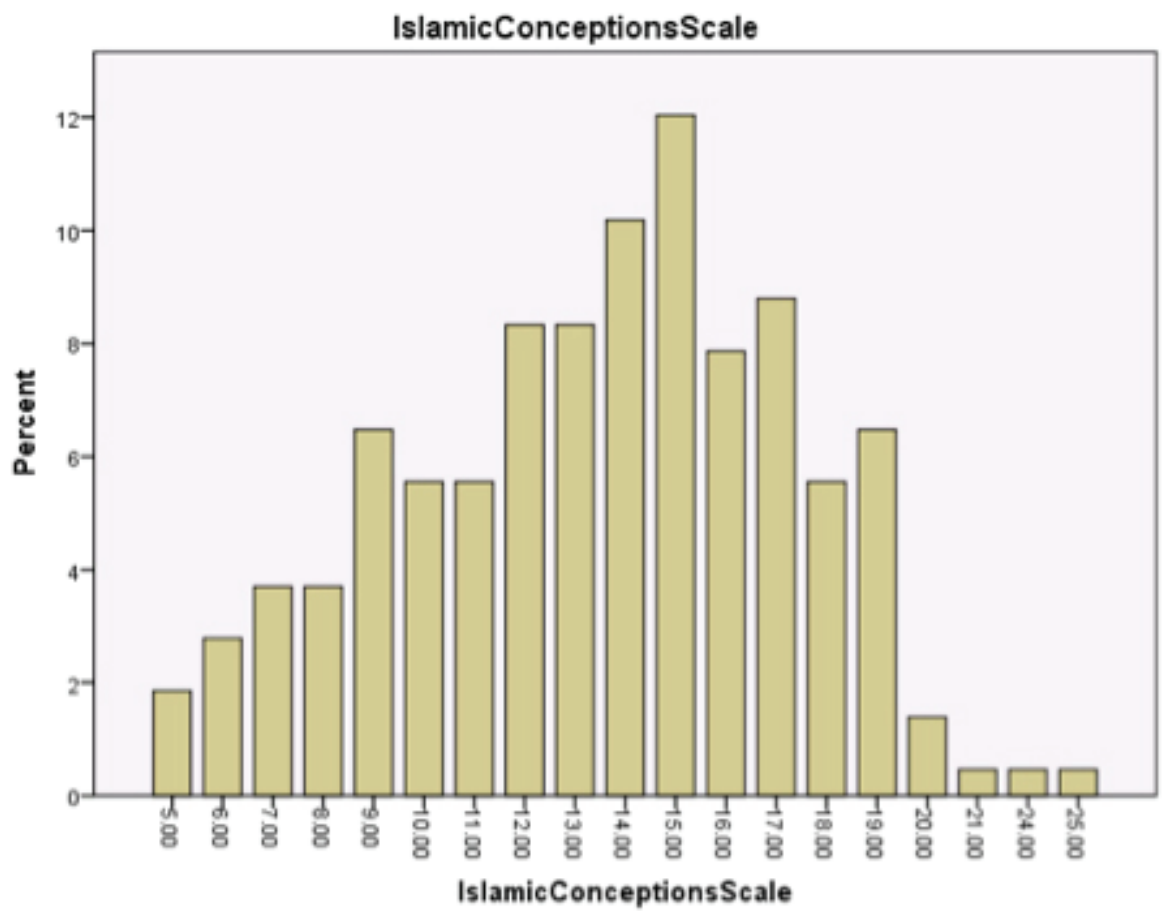

The results of the Western conceptions (see Figure 2) shows that scores ranged from 8 to 32 , with a mean score of $17.9(S D=8.44)$. Although $8.4 \%$ of participants scored in the low range of agreement with Western conception, and $10.7 \%$ had a score in the high agreement range with Western conceptions, the majority, $65.7 \%$, had a score in the moderate range.

The spiritual conceptions scale (Figure 3) consisted of only two questions. Scores ranged from 2 to 10 with a mean score of $3.82(S D=2.56)$. The majority of participants, $41.1 \%$, had a moderate score, $29.8 \%$ had a high score, and $12.5 \%$ had a low score. The remaining percentage (16.6\%) failed to answer the two questions on the scale.

\section{Analysis of Open-Ended Responses}

Responses to open-ended questions reveal a wide range of definitions for mental illness, with only a few respondents mentioning Islam, religion, or spirituality-related terms in their definitions. The majority of participants defined mental illness using concepts and terms that reflect mental illness as a physical, cognitive, or socio-cultural-based problem. In addition, partici- 
Figure 2. Western Conceptions of Mental Illness Subscale - Score Distribution

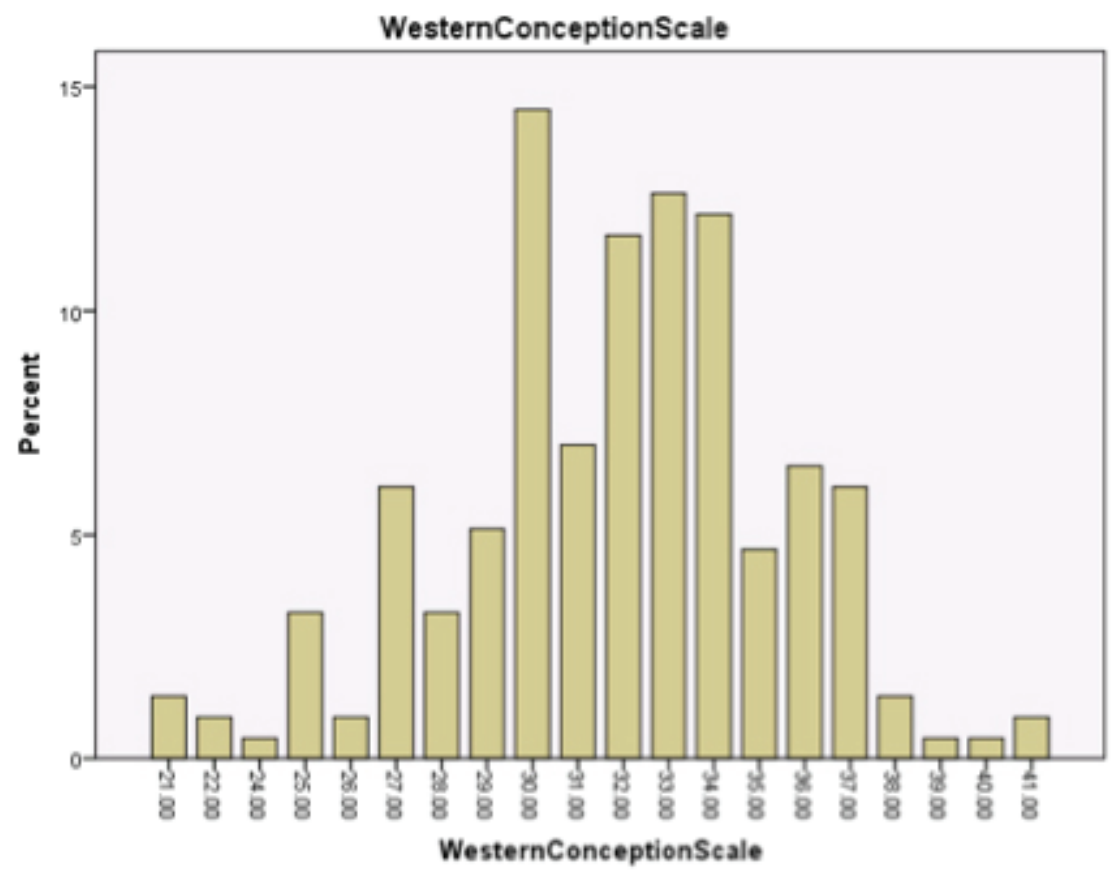

pants identified several causes of mental illness not discussed in the closeended statements.

Of the 255 participants, 190 (about 75\%) responded to an open-ended question asking them to offer their definitions of mental illness. Definitions were analyzed using thematic analysis resulting in three dominant themes: mental illness defined primarily as (a) biomedical (b) psycho-spiritual, or (c) multidimensional. Other themes emerged that, upon further analysis, lacked saliency or could fit within one of these larger themes. Each response was placed into only one category based on keywords such as "disease," "mind," "deviation," and "judgment." Responses were initially broken down into 19 categories. Categories with the least number of responses were re-analyzed to see if they would fit into a larger, broader category. These were narrowed into eight larger, broader categories that encompass the themes of biological, cognitive, deviance, dysfunction, Islamic, multidimensional, specific disorders, and unspecified. These were further condensed into five themes: (a) mental illness defined primarily as physical, (b) cognitive, (c) mental illness as a form of deviance, (d) dysfunction or disability, and (e) mental illness as multidimensional. Upon further analysis it is clear that the bulk of responses correspond to the Western biomedical idea of mental illness, a psycho-spiritual definition typical of tradition Islamic con- 
Figure 3. Spiritual Conceptions of Mental Illness Subscale - Score Distribution

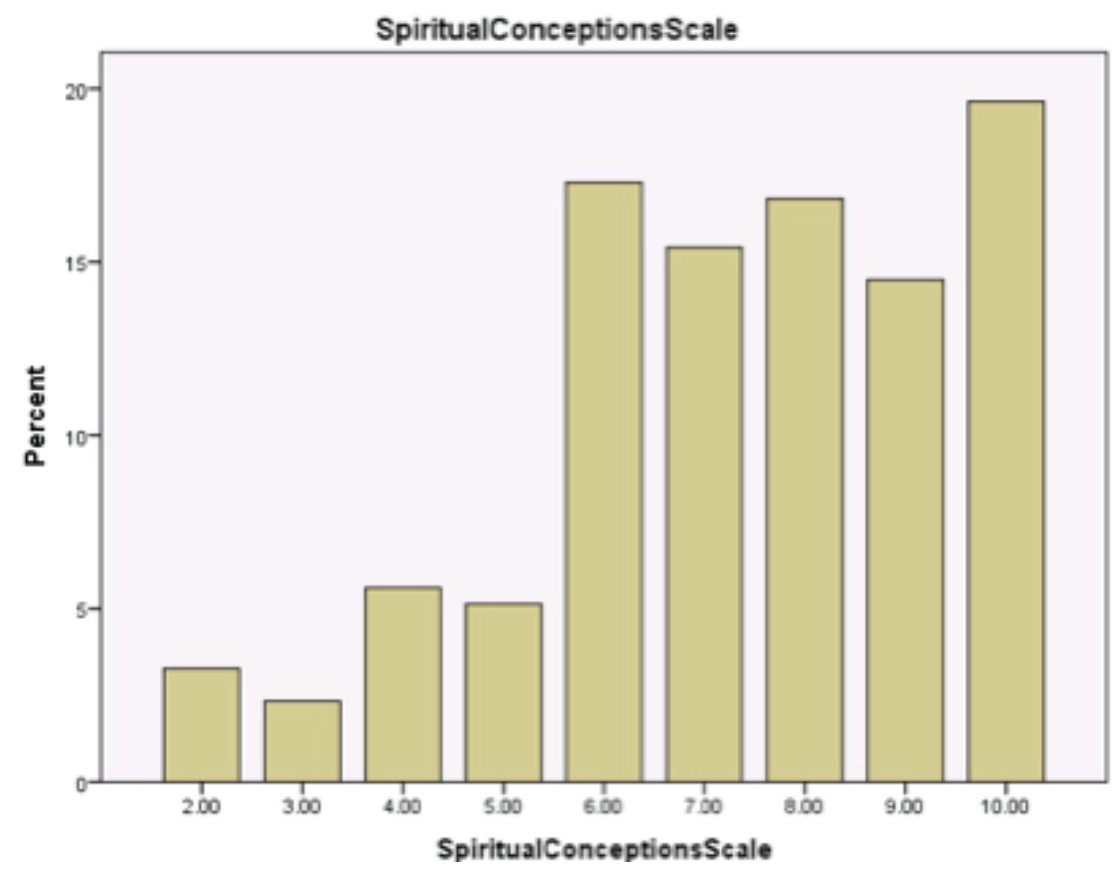

ceptions, or a multidimensional model that encompasses biomedical, social, and sometimes spiritual conceptions.

Within the definition of mental illness as a physical or medical condition, the most common theme that emerged was mental illness as a dysfunction within the brain or a chemical imbalance in the brain; this theme was expressed in 46 of the responses. An example of this definition is: "A chemical imbalance in the brain that manifests itself in mental and sometimes physical symptoms." Twenty-nine responses focused on cognitive and emotional aspects of mental illness. These definitions often specifically referred to problems in judgment and decision-making skills, as well as an inability to think in ways that were considered "normal." Deviance or functioning outside of the social norms was a common theme in 19 of the responses. Some defined mental illness as a state of acting outside of norms, or behaviors that are not acceptable by society. Twenty-four participants defined mental illness using more general terms thematically categorized as "dysfunction" or "impairment."

Only three responses referred specifically to Islam when defining mental illness. One stated that mental illness is "a challenge from Allah that is a legitimate health issue." Another attributes it to both environmental and supernatural issues: "It can be jinn possession or current situation which person [a] is going through, it can be treatable by the help of $d h i k r$ (remembrance of God), 
counseling, and medical doctors." The last response with an Islamic theme is the most detailed, focusing on spiritual and moral deficits within an individual:

Mental illness ultimately is from ALLAH and is the result of false worship. False worship is worshipping created things rather than worshipping AL$\mathrm{LAH}$, the Ultimate Originator and Creator of All Things. Some examples of the creations of ALLAH that some people try to worship include, but certainly are not limited to the following: Messengers and Prophets, celestial bodies, scholars both religious and secular, physicians of the mind, body and spirit, wealth and possessions, spouses, parents. ... Mental illness is a disease or functional disorder of the human mind in consequence of worshipping other than ALLAH. Proximate causes of mental illness may include many things including sinful actions, drugs, alcohol, chemical imbalances in the brain, etc., but the ultimate cause is worshipping other than Allah.

Of the responses, 14 reflect an integrative or multidimensional definition that refers to more than one of these other themes in its definition. These definitions of mental illness, though broader than those found in other thematic categories, reflect a less stringent categorization. The responses of many participants reveal a great deal of thought about what mental illness is or can be, as in this example:

Mental illness covers a broad spectrum of issues to me, ranging from situational depression that might not have a biological or genetic basis to more severe conditions that are determined by a person's biology (such as schizophrenia or bipolar disorder). I would also say that I don't attach any stigma to the idea of "mental illness" as probably everyone at some point in their life will suffer from a state that could be described as a form of "mental illness," be it postpartum depression, posttraumatic stress disorder, or just simply low mood or exhaustion as a result of what I would consider the stressful modern lifestyle.

Fourteen responses specified a disorder or symptom, including dementia, depression, anxiety, hallucinations, schizophrenia, PTSD, and bipolar disorder. 21 of the responses were too vague to be categorized or were synonyms for the term mental illness itself.

The responses to the question, "How do you define mental illness?" suggest a varied conceptualization of mental illness that may be influenced by a variety of factors such as age, gender, culture, or experience. Though generally associated in some way with the brain or the mind, mental illness is also seen as tied to environment, socially accepted norms, and ideas about what is typical functioning. 
Participants were asked to report additional causes of mental illness that they thought may not have been covered in the closed-response questions. The majority of these responses fall under the category of environmental factors. These include abuse and traumatic experiences, stress, divorce, a lack of socialization, and neglect. Specifically, acculturative stress and religious or social pressure were identified as situational factors that could lead to mental illness. One participant described the role of immigration and social factors as a particularly potent cause of mental illness within the Muslim community:

As I mentioned above, I would say that the stress of certain types of lifestyles, especially those of immigrant families who find themselves detached from their original culture and forced to acclimatize to a new place, can lead to certain types of mental illness or at least to a severe confusion about one's identity and where one belongs (which can certainly contribute to feelings of depression).

Other social factors that were attributed to causing mental illness focused on interpersonal and community relationships, as in these responses: "no hope for the future, low self worth, not being accepted by the people around you, domestic violence" and "disturbed life, tragedies (death, divorce), domestic violence, loneliness, no activity." Exposure to toxins, chemicals, prenatal disturbances, and food additives were also viewed as causes of mental illness. These causes were detailed by six respondents. One participant elaborated on what is included in this type of environmental factor:

Mental illness might be caused due to environmental or natural causes such as mercury or lead poisoning, exposure to strong chemicals, radiation, fungus, toxins generated due to contaminated food, a bite from a highly toxic animal such as rabies-infected dogs, bats, or squirrels.

Another dominant theme in responses to causes of mental illness is lack of faith or lack of following Islam. Participants stated that: "Lack of remembrance of Allah and practices designed to help awaken one's self to this remembrance." One respondent stated that the cause of mental illness is "wholeheartedly embracing and promoting various forms of sinful practices and false worship, including false doctrines which promotes concepts of Allah being other than One God will result and manifest in some degrees or forms of mental illnesses." In addition to a lack of faith, weakness in faith was viewed as a cause, as in these examples: "Weakness of iman (faith), weak relationship with Allah," and "Not having strong faith in Allah or true belief."

For others, a religious explanation was viewed as inherent, but by no means in conflict with a biological or environmental cause as found in these examples: 
"I believe that the physical proof is the chemical imbalance but behind that is the Will of Allah," and "Nothing occurs without the Will of the Almighty. However, there are scientific ways the Almighty works through. They could be genetic or from a traumatic experience." The role of supernatural forces was acknowledged in many instances, though not considered the only possible origin for mental illness: "Although the existence of jinn, evil eye, and black magic are very much real and I fully believe in them, $99.9 \%$ of mental illnesses are related to genetic and/or environmental factors. Claims of black magic and jinn almost always end up as cultural superstitions."

Many other respondents thought that the cause of mental illness cannot be determined or is multifaceted in nature, and cannot be attributed to any one cause. One participant articulated:

Mental illness can be caused by abusive peers, parents, siblings, or spouses but not necessarily is caused by the above. Mental illness such as addiction or depression can sometimes be caused by substance abuse but not always. Mental illness can be but not necessarily IS caused by chemical imbalances in the brain. Mental illness can, but not necessarily comes from family tension, living environment, or war.

A combination of factors that are biological, environmental, and spiritual in nature was common in many responses. These statements have been termed multidimensional, because they integrate more than one model of mental illness. The statement of one participant best summarizes this position: "Mental illness is such a vague term that different situations can be the result actions. But I think religious pressures, religion, and biology are all connected with each other."

\section{Discussion}

Muslim Americans generally support a Western view of mental illness; albeit with a flavor from their own cultures and religious traditions. As with many immigrants, Muslims adopt the beliefs, customs, and values of America. Muslim Americans support biological and environmental factors influencing mental illness, such as chemical imbalances in the brain, life stresses and drug abuse. At the same time, many Muslims may also support supernatural causes such as jinn and evil eye, and psycho-spiritual causes such as lack of obedience to God or illness as a test from God. In open-ended responses, Muslim Americans tended to define mental illness from a biomedical perspective, but at the same time were more likely to identify social, environmental, and psycho-spiritual causation for the initial onset of mental illness. 
These findings suggest that the prevailing biomedical model of mental illness promoted by clinicians in the United States fails to address many causes of mental illness accepted by Muslim Americans, ignoring important religious and cultural factors that may determine the onset, progression, and elimination of symptoms. Few practitioners are trained in spiritually competent psychotherapies that acknowledge and work within the framework of beliefs in the role of a higher power on illness, such as dysfunction as the result of sinful behavior or a test from God, beliefs that are no less prevalent in other religious communities in the United States. This study offers a glimpse at beliefs that go beyond the 'mental illness as disease' model, and that must be addressed in order to provide effective services for those who conceptualize their problems in ways that may no longer be considered the norm in modern societies. These beliefs are persistent and valid within both Western and non-Western spiritual and religious contexts.

The thematically varied definitions of mental illness offered by study participants reflect the larger disagreement among both the clinical and lay population in the United States regarding what the term "mental illness" means within the sphere of personal and societal experiences. None of the responses are in complete agreement with the DSM definition of mental illness, suggesting a similar disconnect between lay populations and clinicians as found in recent research (Kuppin \& Carpiano, 2006; Link et al., 1999; Pescosodilo et al., 2000). Responses to both the close-ended and open-ended questions on causes of mental illness suggest a similar disconnect. Open-ended descriptions indicate that Muslim Americans see a relationship between the process of immigration and poor mental health, an idea that has only recently been discussed and researched with the psychological community (see Khuwaja et al., 2007; Kumar \& Nevid, 2010; Schwartz et al., 2010; Trinh et al., 2009). Spiritual causes were also identified, though not nearly as frequently as biomedical and multidimensional causation. Rather than attributing mental illness to supernatural causes such as the evil eye, black magic, or jinn possession as has been found in studies in traditional Muslim societies (Abu-Rabia, 2005; Al-Adawi et al., 2002; Al-Issa, 2000; Ally \& Laher, 2008), participants claimed that lack of faith and God-consciousness, and sinful behaviors are likely to lead to mental illness. Other causes of mental illness identified by Muslim Americans, such as environmental and physical causes, are in agreement with the general American lay population, who also identified chemical imbalance, stress, childhood experiences, genetics, stress, and bad character as causes of mental illness in previous studies (Kuppin \& Carpiano, 2006).

The present research provides insight into the many ways mental illness is viewed and defined among Muslim clients. Practitioners should take the time to address symptoms with the client to gain an idea of how the client conceptualizes his or her current state. If traditional Islamic beliefs or other 
non-Western ideas about causation or attribution are made, the practitioner may need to reassess a planned course of treatment, and consider integrating spiritual methods into his or her approach. Education and training of both health care practitioners and community members is a necessary step toward improving health service utilization in the Muslim American community.

\section{Limitations}

This present study has several weaknesses. First, the sample may not be representative in terms of ethnic variety, age, gender, level of education, and religious orientation because of the convenient sampling method. The method of data collection at mosques was limited in that it reached only those who are active mosque attendees, or actively engaged in Islamic organizations or events. Another weakness of this method was reaching more men than women, due to the fact that a larger number of men attend Friday prayer services. In addition, many of the respondents are young and highly educated, which may play a significant role in the outcome of the study. Second, the sample size is small. The convenience sample, in combination with the small sample size, makes it impossible to generalize the results as representing the general beliefs and attitudes of all Muslim Americans. Muslim Americans are not a monolithic population; while Muslim Americans do share a common religious heritage, they also belong to various sects and have varying level of adherence to core religious practices. In addition to a population of American-born Muslims, Muslim American immigrants originate from a variety of countries and have been in America various lengths of time. It is impossible to parse out all the variations with such a small sample size. Further research is needed to determine if attitudes and beliefs about mental health are more influenced by particular cultural contexts than common religious orientation, as has been asserted by previous research with Muslim populations in the United States (see Haque, 2004; Kemp, 2007; Kobeisy, 2004; Martin, 2009).

\section{Conclusion}

The primary purpose of this research was to expand the current knowledge regarding Muslim Americans' beliefs and attitudes toward mental illness. Such a study operates within the caveat that Muslims Americans are a distinct subset of the American population, but also possess a variety of cultural, ethnic, and national backgrounds. Muslim Americans hold diverse and sometimes conflicting beliefs regarding the definition and causes of mental illness, the most appropriate and effective method of therapy, and the ability of mental health professionals in the United States to understand their problems. Continued research in 
this area will enhance our understanding of how Muslim Americans apply their beliefs regarding mental health, and approach available interventions.

The present study provides insight for practitioners into the many ways mental illness is viewed and defined in the Muslim American community. In general, it appears that most Muslim Americans prefer a holistic approach to handling mental health issues, taking account of physical, emotional, and spiritual aspects of an illness or problem. The results suggest that a practitioner cannot proceed with an intervention without understanding religious or cultural differences that may impede communication and progress in therapy.

The findings show that Muslim Americans may differ from other minority populations in conceptions of mental illness in that they offer additional explanations for the cause of mental illness, and are open to varying interpretations of mental illness. The results serve to dispel the view that Muslim Americans are a monolithic group with one shared point of view on mental illness, or the idea that, because of religious beliefs or level of conformity to American norms, they reject explanations and treatments for mental illness that have arisen from the Western medical model. The responses to open-ended questions serve to increase an understanding of how traditional conceptions of mental illness are manifested in personal experiences, as well as how the personal experiences inform participants' beliefs and attitudes. The study findings demonstrate some unique aspects of Muslim American conceptions of mental illness, while at the same time, support current research in the American lay population of a broader, more scientific-based understanding of mental illness.

\section{References}

Abu-Rabia, A. (2005). The evil eye and cultural beliefs among the Bedouin tribes of the Negev, Middle East. Folklore, 116, 241-254. doi:10.1080/00155870500282677

Al-Adawi, S., Dorvlo, A. S., Al-Ismaily, S. S., Al-Ghafry, D. A., Al-Noobi, B. Z., AlSalmi, A., et al. (2002). Perception of and attitude towards mental illness in Oman. International Journal of Social Psychiatry, 48, 305-317. http://dx.doi. org/10.1177/002076402128783334

Alawi, A. H. (1992). The Qur'anic concept of mental health. In Z. A. Ansari (Ed.), Quranic concepts of human psyche (pp. 87-97). Islamabad, Pakistan: Islamic Research Institute Press.

Al-Issa, I. (2000). Culture and mental illness in Algeria. In I. Al-Issa (Ed.), Al-Junun: Mental illness in the Islamic world (pp. 101-119). Madison, CT: International Universities Press.

Ally, Y., \& Laher, S. (2008). South African Muslim faith healers' perceptions of mental illness: Understanding, Aetiology and Treatment. Journal of Religion and Health, 47, 45-56. doi:10.1007/s10943-007-9133-2

Al-Subaie, A., \&Alhamad, A. (2000). Psychiatry in Saudi Arabia. In I. Al-Issa (Ed.), Al-Junun: Mental illness in the Islamic world (pp. 205-233). Madison, CT: International Universities Press. 
Aloud, N., \& Rathur, A. (2009). Factors affecting attitudes toward seeking and using formal mental health and psychological services among Arab Muslim populations. Journal of Muslim Mental Health, 4, 79-103. http://dx.doi. org/10.1080/15564900802487675

Ameen, A. (1992). The Jinn \& Human Sickness: Remedies in the light of the Qur'aan \& Sunnah. (N., Al-Khattab, Trans, 2005). Riyadh, Saudi Arabia: Darussalam.

Amer, M. M., Hovey, J. D., \& Fox, C. M., \& Rezcallah, A. (2008). Initial development of the Brief Arab Religious Coping Scale. Journal of Muslim Mental Health, 3, 69-88. http://dx.doi.org/10.1080/15564900802156676

Athar, S. (Ed.). (1993). Islamic perspectives in medicine: A survey of Islamic medicine: Achievements \& contemporary issues. Indianapolis, IN: American Trust Publications.

Azhar, M. Z., \& Varma, S. L. (2000). Mental illness and its treatment in Malaysia. In I. Al-Issa (Ed.), Al-Junun: Mental illness in the Islamic world (pp. 163-186). Madison, CT: International Universities Press.

Bali, W. (2004). Sword against black magic and evil magicians (C. Abdelghani, Trans). London: Al-Firdous Ltd.

Coughlan, R., \& Owens-Manley, J. (2005). Bosnian refugees in America: New communities, new cultures. New York: Springer.

El-Islam, M. F. (2000). Mental illness in Kuwait and Qatar. In I. Al-Issa (Ed.), Al-Junun: Mental illness in the Islamic world (pp. 121-137). Madison, CT: International Universities Press.

El-Zein, A. (2009). Islam, Arabs, and the intelligent wordld of the jinn. New York: Syracuse University Press.

Endrawes, G., O’Brien, L., \& Wilkes, L. (2007). Mental illness and Egyptian families. International Journal of Mental Health Nursing, 16, 178-187. doi:10.1111/j.1447-0349.2007.00465.x

Fadlalla, A. H. (2005). Modest women, deceptive jinn: Identity, alterity, and disease in Eastern Sudan. Identities: Global Studies in Culture and Power, 12, 143-174. doi: $10.1080 / 10702890490950556$

Farooqi, Y. (2006). Traditional healing practices sought by Muslim psychiatric patients in Lahore, Pakistan. International Journal of Disability, Development and Education, 53(4), 401-415. doi:10.1080/10349120601008530

Gomez, M. A. (1994). Muslims in early America. The Journal of Southern History, 60, 671-710. http://dx.doi.org/10.2307/2211064

Haddad, Y. (2004). Not quite American? The shaping of Arab and Muslim identity in the United States. Waco, Texas: Baylor University Press.

Hammoud, M. M., White, C. B., and Fetters, M. D. (2005). Opening cultural doors: Providing culturally sensitive healthcare to Arab American and American Muslim patients. American Journal of Obstetrics and Gynecology, 193, 1307-1311. http:// dx.doi.org/10.1016/j.ajog.2005.06.065

Haque, A. (2004). Religion and mental health: The case of American Muslims. Journal of Religion and Health, 43(1), 45-58. http://dx.doi.org/10.1023/ B:JORH.0000009755.25256.71

Haque, A. (2008). Culture-bound syndromes and healing practices in Malaysia. Mental Health, Religion \& Culture, 11, 685-696. http://dx.doi. org/10.1080/13674670801958867

Haque, A. (2010). Mental health concepts in Southeast Asia: Diagnostic consider- 
ations and treatment implications. Psychology, Health \& Medicine, 15(2), 127-134. doi:10.1080/13548501003615266

Harland, R., Antonova, E., Owen, G. S., Broome, M., Landau, S., Deeley, Q., et al. (2009). A study of psychiatrists' concepts of mental illness. Psychological Medicine, 39, 967-976. doi:10.1017/S0033291708004881

Hedayat-Diba, Z. (2000). Psychotherapy with Muslims. In P. S. Richards \& A. E. Bergin (Eds.), Handbook of psychotherapy and religious diversity (pp. 289-314). Washington, DC: American Psychological Association. http://dx.doi.org/10.1037/10347012

Husain, A. (2006). Islamic psychology: Emergence of a new field. New Delhi, India: Global Vision Publishing House.

Husain, S. A. (1998). Religion and mental health from the Muslim perspective. In H. G. Koenig (Ed.), Handbook of religion and mental health (pp. 279-291). San Diego, CA: Academic Press. http://dx.doi.org/10.1016/B978-012417645-4/50087-0

Johnsdotter, S., Ingvarsdotter, K., Ostman, M., \&Carlbom, A. (2011). Koran reading and negotiation with jinn: strategies to deal with mental ill health among Swedish Somalis. Mental Health, Religion, \& Culture, 14(8), 741-755. http://dx.doi.org/10. 1080/13674676.2010.521144

Kemp, C. (2007). Iraqis. Refugee Health, Immigrant Health. Retrieved from https://bearspace.baylor.edu/Charles_Kemp/www/iraqi_refugees.htm

Khuwaja, S. A., Selwyn, B. J., Kapadia, A., McCurdy, S., \& Khuwaja, A. (2007). Pakistani Ismaili Muslim adolescent females living in the United States of America: Stresses associated with the process of adaptation to U.S. culture. Journal of Immigrant and Minority Health, 9, 35-42. http://dx.doi.org/10.1007/s10903-006-9013-y

Kobeisy, A. N. (2004). Counseling American Muslims: Understanding the faith and helping the people. Westport, CT: Praeger.

Kumar, A., \& Nevid, J. S. (2010). Acculturation, enculturation, and perceptions of mental disorders in Asian Indian immigrants. Cultural Diversity and Ethnic Minority Psychology, 16, 274- 283. http://dx.doi.org/10.1037/a0017563

Kuppin, S., \& Carpiano, R. (2006). Public conceptions of serious mental illness and substance abuse, their causes and treatment: Findings from the 1996 General Social Survey. American Journal of Public Health, 96, 1766-1771. doi:10.2105/ AJPH.2004.060855

Link, B. G., Phelan, J. C., Bresnahan, M., Stueve, A., \& Pescosolido, B. A. (1999). Public conceptions of mental illness: Labels, causes, dangerousness, and social distance. American Journal of Public Health. 89, 1328-1333. http://dx.doi.org/10.2105/ AJPH.89.9.1328

Martin, S. S. (2009). Illness of the mind or illness of the spirit? Mental health-related conceptualization and practices of older Iranian immigrants. Health \& Social Work, 34(2), 117-125. http://dx.doi.org/10.1093/hsw/34.2.117

Mubbashar, M. H. (2000). Mental illness in Pakistan. In I. Al-Issa (Ed.), Al-Junun: Mental illness in the Islamic world (pp. 187-203). Madison, CT: International Universities Press.

Nyang, S. (1999). Islam in the United States of America. Chicago: ABC International Group, Inc.

Pescosolido, B. A., Martin, J. K., Link, B. G., Kikuzawa, S., Burgos, G., Swindle, R., et al. (2000). Americans'views of mental health and illness at century's end: Continuity and change. Public report on the MacArthur mental health module 1996 general 
social survey. Bloomington, IN: Indiana Consortium of Mental Health Services Research.

Pew Research Center (2007). Muslim Americans: Middle class and mostly mainstream. Washington, DC: Pew Research Center.

Ratliff, S. K. (1997). Caring for Cambodian Americans: A multidisciplinary resource for the helping professions. New York: Gerald Publishing.

Rippy, A. E., \& Newman, E. (2008).Adaptation of a scale of race-related stress for use with Muslim Americans. Journal of Muslim Mental Health, 3, 53-68. http://dx.doi. org/10.1080/15564900802035292

Rippy, A. E., \& Newman, E. (2006). Perceived religious discrimination and its relationship to anxiety and paranoia among Muslim Americans. Journal of Muslim Mental Health, 1, 5-20. http://dx.doi.org/10.1080/15564900600654351

Saeed, K., Gater, R., Hussain, A., \& Mubbashar, M. (2000). The prevalence, classification and treatment of mental disorders among attenders of native faith healers in rural Pakistan. Social Psychiatry and Psychiatric Epidemiology, 35, 480-485. http:// dx.doi.org/10.1007/s001270050267

Snhnittker, J., Freese, J. \& Powell, B. (2000). Nature, nuture, neither, nor: Black-white differences in beliefs about the causes and the appropriate treatment of mental illness. Social Forces, 78(3), 1101-1130. http://dx.doi.org/10.1093/sf/78.3.1101

Schwartz, S. J., Unger, J. B., Zamboanga, B. L., \& Szapocznik, J. (2010). Rethinking the concept of acculturation: Implications for theory and research. American Psychologist, 65, 237-251. doi:10.1037/a0019330

Shafii, M. (1988). Freedom from the self: Sufism, meditation and psychotherapy. New York: Human Sciences Press.

Speziale, F. (2003). Tradition \& modernization of Islamic psychiatric care in the subcontinent. IIAS Newsletter, 30, 11.

Stein, D. (2000). Views of mental illness in Morocco: Western medicine meets the traditional symbolic. Canadian Medical Association Journal, 163, 1468-1470. doi:10.1891/1559-4343.11.2.120

Stone, C. (1991). Estimate of Muslims living in America. In Y. Y. Haddad (Ed.), The Muslims of America. New York: Oxford University Press.

Trinh, N-H., Rho, Y. C., Lu, F. G., \& Sanders, K. M. (Eds.). (2009). Handbook of mental health and acculturation in Asian American families. New York: Humana Press. Wesselmann, E. D. \& Graziano, W. G. (2010). Sinful and/or possessed? Religious beliefs and mental illness stigma. Journal of Social and Clinical Psychology, 29, 402-437.

Williamson, W. P., \& Ahmad, A. (2007). Survey research and Islamic fundamentalism: A question about validity. Journal of Muslim Mental Health, 2, 155-176. http:// dx.doi.org/10.1080/15564900701614809

Wormser, R. (2002). American Islam: Growing up Muslim in America. New York: Walker \& Company. 